\title{
SPECIFICITY OF THE INTERACTION OF GENOTYPES WITH CONTRASTING ENVIRONMENTS
}

\author{
JEAN M. PERKINS and J. L. JINKS \\ Department of Genetics, University of Birmingham, Birmingham B15 2TT
}

Received 1.viii.70

\section{THE PROBLEM}

Following the work of Mather (1946, 1953) and Jinks and Mather (1955), evidence has accumulated which shows that the magnitude of the interaction of a genotype with the environment, whether ascribable to developmental instability or phenotypic plasticity (Thoday, 1953; Westerman and Lawrence, 1970) is subject to genetical control. The application of linear regression analysis to such interactions (see Finlay and Wilkinson (1963), Perkins and Jinks (1968a) and Freeman and Perkins (1971) for reviews) although not a prerequisite for quantifying and analysing the interaction, has accelerated progress because of the simplicity of the approach and the prospective predictive value of the parameters estimated.

Given a satisfactory and simple method of quantifying the interaction and evidence of its genetical control it is possible to design an appropriate breeding programme to select for any desired level of interaction. The latter will, of course, differ for different kinds of environmental variables. For uncontrollable variables such as differences between seasons the desired level of interaction would normally be as low as possible to give maximum uniformity of performance over seasons. For controllable variables such as level of fertiliser application the desired level of interaction could well be as high as possible to produce maximum increase in performance per unit of fertiliser added.

Selection for the desired level of interaction, therefore, raises a fundamental problem, namely, the extent to which selection to the desired level of interaction for one kind of environmental variable leads to the same level of interaction for a different kind of environmental variable. It may be advantageous, for example to the breeder, to have a general level of interaction with environmental variables of more than one kind so that the desired level of interaction with seasonal differences can be selected for in less costly kinds of environments such as a range of sowing dates in the same season. On the other hand, it may be equally desirable to have some degree of specificity of the levels of interaction with different kinds of environmental variables so that genotypes can be selected which combine a low level of interaction with uncontrollable variables with a high level of response to controllable variables.

In the present paper this problem is investigated by measuring the interactions of genotypes selected for their low and high levels of interaction with seasonal differences when exposed to environmental variables such as different sowing dates and controlled differences in fertiliser applications. 


\section{SElection of High AND LOW GENOTYPES}

The two inbred lines used in these investigations were chosen from among the 29 inbred lines of Nicotiana rustica which were compared over 10 locations and seasons for the two characters, final height and flowering time by Perkins and Jinks $(1968 a, 1968 b)$. They were chosen on the criteria that they should be the least and most sensitive to environmental variation for final height while differing as little as possible for flowering time so as to provide two contrasting situations for comparison over the different kinds of environments. Inbred varieties 2 and 42 came nearest to satisfying these criteria (see tables 5 and 3, Perkins and Jinks (1968a, 1968b) respectively).

\section{The environments}

Two contrasting kinds of environments were used. The first, chosen as an easily manipulated, uncontrollable environmental difference, consisted of eight successive sowings at weekly intervals which covered the period from the earliest to the latest date that $\mathcal{N}$. rustica can be successfully sown in the Birmingham area. These environments were repeated in two seasons, 1968 and 1969 (sets 2 and 3). The second, chosen as typical of controlled environmental differences, was the eight combinations of presence and absence of nitrogenous, potassic and phosphatic fertilisers on plots of ground which had been receiving these fertiliser treatments for over 20 years. Two such sets were again grown, both in 1968, by combining these eight combinations with the presence and absence of lime (sets 4 and 5). As a control of the seasonal environmental differences eight seasons were chosen from the set available up to 1969 on the criterion that they came nearest to matching the levels of replication used in the four new sets of environments (set l).

Although in one sense the environmental differences produced by sowing at weekly intervals are controlled by the date of sowing, they are used here as a typical set of uncontrolled environments in that the differences that arise are the unpredictable consequences of differences in rainfall, sunlight and humidity as well as the regular and more predictable consequences of changes in daylength.

\section{EXPERIMENTAL DEsign}

For the two sets of successional sowing the standard design of five individually randomised plants of each family in each of the two replicate blocks was used in each environment. For the two sets of fertiliser treatments, however, the nature and shape of the areas available required a different design. The best use of these areas was achieved by growing 15 individually randomised plants of each family in each environment without replication. Four kinds of families were grown, the selected, inbreds 2 and 42 , and both of their reciprocal $F_{1}$ families.

Final height was measured in centimetres and this necessitated the conversion of seasonal data prior to 1968 to centimetres from the original measurements in inches. Flowering time was scored as the number of days from sowing to the opening of the first flower. 


\section{Analyses}

\section{(i) Inbreds}

The means of the two inbreds for final height and flowering time in each of the eight environments within each of the five sets are presented in table 1. An analysis of variance of these data is summarised in table 2. Since genotypes (item 1) and environmental sets (item 2) are fixed effects,

TABLE 1

(a) Means for the final height of varieties 2 and 42 in each of the 8 environments for each of the five environmental sets

\begin{tabular}{|c|c|c|c|c|c|c|c|c|c|c|}
\hline \multirow{3}{*}{$\begin{array}{l}\text { Environ- } \\
\text { ment }\end{array}$} & \multicolumn{10}{|c|}{ Environmental set } \\
\hline & \multicolumn{2}{|c|}{ I } & \multicolumn{2}{|c|}{2} & \multicolumn{2}{|c|}{3} & \multicolumn{2}{|c|}{4} & \multicolumn{2}{|c|}{5} \\
\hline & 2 & 42 & 2 & 42 & 2 & 42 & 2 & $42^{\prime}$ & 2 & 42 \\
\hline 1 & $93 \cdot 7$ & $103 \cdot 4$ & $122 \cdot 3$ & $146 \cdot 1$ & $96 \cdot 6$ & $114 \cdot 2$ & $26 \cdot 1$ & $43 \cdot 6$ & 67.8 & $87 \cdot 1$ \\
\hline 2 & $123 \cdot 9$ & $120 \cdot 8$ & 112.2 & $122 \cdot 3$ & $108 \cdot 4$ & 118.8 & $51 \cdot 4$ & $69 \cdot 2$ & $55 \cdot 7$ & $79 \cdot 9$ \\
\hline 3 & $84 \cdot 3$ & 89.9 & 112.0 & 132.0 & $110 \cdot 4$ & $122 \cdot 1$ & $41 \cdot 1$ & 62.1 & $56 \cdot 8$ & $83 \cdot 4$ \\
\hline 4 & 93.5 & $73 \cdot 7$ & 112.6 & $126 \cdot 8$ & $106 \cdot 8$ & $120 \cdot 6$ & $45 \cdot 1$ & $56 \cdot \mathrm{I}$ & $53 \cdot 3$ & 84.2 \\
\hline 5 & $114 \cdot 6$ & 137.9 & 109.7 & 131.7 & 113.8 & 121.5 & $38 \cdot 1$ & 64.9 & 52.5 & $74 \cdot 6$ \\
\hline 6 & $100 \cdot 2$ & 116.8 & $109 \cdot 3$ & $128 \cdot 4$ & 118.8 & $129 \cdot 1$ & $27 \cdot 6$ & $47 \cdot 8$ & $51 \cdot 5$ & $70 \cdot 5$ \\
\hline 7 & 107.6 & 91.4 & 101.4 & 121.0 & $118 \cdot 2$ & $145 \cdot 0$ & 47.9 & 69.0 & $60 \cdot 6$ & 80.5 \\
\hline 8 & $108 \cdot 3$ & $110 \cdot 6$ & 99.6 & 116.5 & $109 \cdot 4$ & $140 \cdot 3$ & $52 \cdot 4$ & 78.8 & $57 \cdot 5$ & $70 \cdot 2$ \\
\hline
\end{tabular}

(b) Means for the flowering time of varieties 2 and 42 in each of the 8 environments for each of the 5 environmental sets

Environmental set

\begin{tabular}{|c|c|c|c|c|c|c|c|c|c|c|}
\hline \multirow[b]{2}{*}{$\begin{array}{l}\text { Environ- } \\
\text { ment }\end{array}$} & \multicolumn{2}{|c|}{ I } & \multicolumn{2}{|c|}{2} & \multicolumn{2}{|c|}{3} & \multicolumn{2}{|c|}{4} & \multicolumn{2}{|c|}{5} \\
\hline & 2 & 42 & 2 & 42 & 2 & 42 & 2 & 42 & 2 & 42 \\
\hline 1 & $80 \cdot 5$ & 75.9 & $105 \cdot 3$ & $82 \cdot 3$ & $103 \cdot 7$ & $89 \cdot 8$ & $132 \cdot 0$ & 83.5 & $125 \cdot 1$ & $78 \cdot 4$ \\
\hline 2 & $92 \cdot 4$ & 83.5 & $108 \cdot 0$ & $83 \cdot 4$ & $101 \cdot 4$ & 83.9 & $134 \cdot 5$ & $81 \cdot 1$ & $108 \cdot 3$ & $78 \cdot 3$ \\
\hline 3 & $94 \cdot 6$ & $77 \cdot 8$ & $106 \cdot 1$ & $79 \cdot 2$ & $94 \cdot 7$ & $79 \cdot 4$ & $120 \cdot 7$ & $78 \cdot 6$ & $103 \cdot 7$ & 806 \\
\hline 4 & $103 \cdot 4$ & $87 \cdot 4$ & $101 \cdot 0$ & $80 \cdot 3$ & $89 \cdot 7$ & $76 \cdot 5$ & $122 \cdot 7$ & $86 \cdot 8$ & $101 \cdot 3$ & $79 \cdot 7$ \\
\hline 5 & $108 \cdot 4$ & $92 \cdot 5$ & $100 \cdot 5$ & $81 \cdot 3$ & $104 \cdot 1$ & $73 \cdot 9$ & $140 \cdot 1$ & $79 \cdot 7$ & $104 \cdot 4$ & $76 \cdot 9$ \\
\hline 6 & $95 \cdot 1$ & $75 \cdot 5$ & $107 \cdot 7$ & $78 \cdot 1$ & $96 \cdot 1$ & $69 \cdot 5$ & $141 \cdot 8$ & $81 \cdot 0$ & $105 \cdot 9$ & $78 \cdot 2$ \\
\hline 7 & $117 \cdot 6$ & $93 \cdot 8$ & $97 \cdot 3$ & $80 \cdot 4$ & $97 \cdot 9$ & $73 \cdot 7$ & $121 \cdot 8$ & $81 \cdot 4$ & $111 \cdot 1$ & $77 \cdot 8$ \\
\hline 8 & $101 \cdot 4$ & $73 \cdot 3$ & 94.5 & $73 \cdot 8$ & $100 \cdot 9$ & $70 \cdot 8$ & $122 \cdot 9$ & $80 \cdot 1$ & $120 \cdot 5$ & $84 \cdot 1$ \\
\hline
\end{tabular}

they and their interaction (item 3) must be tested against item 4 (environments within environmental sets). Environments within sets are fixed effects for the fertiliser sets, but they could be regarded as random effects for the seasonal and successive sowing sets. Item 4, therefore, may be tested against item 6 or item 5, if the latter is significantly greater than item 6 , according to whether we regard all environments within sets as fixed or random effects, respectively. In table 2 both tests are given with the same result.

Apart from item 3 (genotypes $\times$ environmental sets) which is not significant for final height and significant at the 1 to 5 per cent. level for flowering time, all other items in table 2 are highly significant. There is, therefore, significant interaction between the two genotypes and the eight environments 
within the sets for both characters and between the genotypes and the environmental sets for flowering time only.

The nature of the significant interaction with environments within sets

TABLE 2

Analyses of variance for the two characters final height and flowering time of inbred lines 2 and 42 when grown in 5 sets of environments consisting of 8 seasons, 8 successive sowings in each of two years and two series of 8 fertiliser treatments

\begin{tabular}{|c|c|c|c|c|c|c|c|c|}
\hline & & & & Char & & & & \\
\hline & & & inal height & & & Flow & ering time & \\
\hline $\mathrm{em}$ & d.f. & M.S. & & Test & d.f. & M.S. & & est \\
\hline & 1 & $4958 \cdot 10$ & V.R. (4)† & $24 \cdot 76 * * *$ & 1 & $15593 \cdot 32$ & V.R. (4) & $247 \cdot 59 * * *$ \\
\hline hental sets & 4 & $15257 \cdot 39$ & V.R. (4) & $76 \cdot 18 * * *$ & 4 & 756.59 & V.R. (4) & $12 \cdot 01 * * *$ \\
\hline imental sets & 4 & $244 \cdot 21$ & V.R. (4) & $1 \cdot 22$ N.S. & 4 & $608 \cdot 63$ & V.R. (4) & $9 \cdot 66^{*}$ \\
\hline $\begin{array}{l}\text { ents within } \\
\text { imental sets }\end{array}$ & 35 & $200 \cdot 28$ & $\begin{array}{l}\chi^{2}(6) \\
\text { V.R. (5) }\end{array}$ & $\begin{array}{r}1095 \cdot 98 * * * \\
5 \cdot 40 * * *\end{array}$ & 35 & $62 \cdot 98$ & $\begin{array}{l}\chi^{2}(6) \\
\text { V.R. (5) }\end{array}$ & $\begin{array}{c}485 \cdot 62 * * * \\
2 \cdot 26 *\end{array}$ \\
\hline $\begin{array}{l}\text { es } \times \\
\text { nments withi } \\
\text { nmental sets }\end{array}$ & 35 & 37.09 & $\chi^{2}(6)$ & $202 \cdot 99 * * *$ & 35 & $27 \cdot 89$ & $\chi^{2}(6)$ & $215 \cdot 07 * * *$ \\
\hline & 829 & $6 \cdot 40$ & & - & 843 & $4 \cdot 54$ & & - \\
\hline
\end{tabular}

\section{Error}

1. Genotypes

2. Environmental sets

3. Genotypes $x$ environmental sets

4. Environments within environmental sets

5. Genotypes $\times$ environments within
environmental sets

$*$ Probability $=0.01-0.05$.

* Probability $=0.001-0.01$.

Probability $<0.001$.

$\dagger$ The number in the brackets refers to the item used as the denominator in the variance ratio or $\chi^{2}$ test of significance.

can be examined by comparing the variances over the eight environments in each set of the two inbred lines. These variances, each for seven degrees of freedom, are listed for the two characters in columns 4 and 6 of table 3.

TABLE 3

The means and variances of the eight environments within each of the five sets for final height and flowering time of inbred lines 2 and 42. Also the linear regression coefficients $(\beta)$ for the linear component of the genotype $\times$ environment interaction for flowering time

\begin{tabular}{|c|c|c|c|c|c|c|}
\hline \multirow[b]{2}{*}{ Set } & \multirow[b]{2}{*}{ Line } & \multicolumn{2}{|c|}{ Final height } & \multicolumn{2}{|c|}{ Flowering time } & \multirow[b]{2}{*}{$\beta$} \\
\hline & & Mean & Variance & Mean & Variance & \\
\hline \multirow[t]{2}{*}{1} & 2 & $103 \cdot 26$ & $164 \cdot 91$ & $99 \cdot 18$ & $125 \cdot 65$ & $0 \cdot 19$ \\
\hline & 42 & $105 \cdot 56$ & $413 \cdot 62$ & $82 \cdot 46$ & $64 \cdot 57$ & $-0 \cdot 19$ \\
\hline \multirow[t]{2}{*}{2} & 2 & $109 \cdot 89$ & 49.93 & $102 \cdot 55$ & $25 \cdot 05$ & $0.33 *$ \\
\hline & 42 & $128 \cdot 10$ & $81 \cdot 79$ & $79 \cdot 85$ & $8 \cdot 76$ & $-0 \cdot 33^{*}$ \\
\hline \multirow[t]{2}{*}{3} & 2 & $110 \cdot 30$ & $50 \cdot 18$ & $98 \cdot 56$ & $24 \cdot 36$ & -0.25 \\
\hline & 42 & $126 \cdot 45$ & 118.45 & $77 \cdot 19$ & $47 \cdot 48$ & 0.25 \\
\hline \multirow[t]{2}{*}{4} & 2 & $41 \cdot 21$ & $101 \cdot 74$ & $129 \cdot 56$ & $74 \cdot 49$ & $0.91 * * *$ \\
\hline & 42 & $61 \cdot 44$ & $137 \cdot 71$ & $81 \cdot 53$ & 6.59 & $-0.91 * * *$ \\
\hline \multirow[t]{2}{*}{5} & 2 & $56 \cdot 96$ & $27 \cdot 97$ & $110 \cdot 04$ & $72 \cdot 27$ & $0.75^{* *}$ \\
\hline & 42 & $78 \cdot 80$ & $40 \cdot 54$ & $79 \cdot 25$ & $5 \cdot 13$ & $-0.75 * *$ \\
\hline
\end{tabular}

In the absence of genotype $\times$ environment interactions the variances of the two inbred lines would be the same in any environmental set. In fact, 2 has a lower variance than 42 in each of the five sets for final height and the larger variance in all except set 3 (successive sowings in 1968) 
for flowering time. Therefore, 2 is consistently less sensitive to the environmental variation within sets for final height and more sensitive in four of the five sets for flowering time.

Where the linear component of the interaction of genotype with macroenvironments accounts for a significant portion of the total interaction variance the appropriate linear regression coefficients provide simple and convenient measures of the relative sensitivities of different genotypes to environmental variation and a means of comparing these sensitivities over different kinds of environments. The partitioning of the interaction of 2 and 42 with the environments within sets into their linear and non-linear components is summarised in table 4 .

\section{TABLE 4}

Foint linear regression analyses of interactions for the two characters final height and flowering time of inbred lines 2 and 42

\begin{tabular}{|c|c|c|c|c|c|c|c|c|}
\hline & \multicolumn{8}{|c|}{ Character } \\
\hline & & & Final height & & & & wering tim & \\
\hline & d.f. & M.S. & $\mathrm{Te}$ & & d.f. & M.S. & & Test \\
\hline $\begin{array}{l}\text { ression } \\
\text { neity of } \\
\text { ion }\end{array}$ & $\begin{array}{l}1 \\
4\end{array}$ & $\begin{array}{r}276 \cdot 00 \\
11 \cdot 79\end{array}$ & $\begin{array}{l}\text { V.R. }(2+3) \\
\text { V.R. }(3)\end{array}$ & $\begin{array}{r}\dagger 9 \cdot 18 * * \\
<1 \quad \text { N.S. }\end{array}$ & $\begin{array}{l}1 \\
4\end{array}$ & $\begin{array}{r}199 \cdot 15 \\
68 \cdot 09\end{array}$ & $\begin{array}{l}\text { V.R. (2) } \\
\text { V.R. (3) }\end{array}$ & $\begin{array}{l}2 \cdot 92 \text { N.S. } \\
4 \cdot 05^{* *}\end{array}$ \\
\hline & $\begin{array}{r}30 \\
829\end{array}$ & $\begin{array}{r}32 \cdot 50 \\
6 \cdot 40\end{array}$ & $\chi^{2}(4)$ & $152 \cdot 46 * * *$ & $\begin{array}{r}30 \\
843\end{array}$ & $\begin{array}{r}16 \cdot 82 \\
4 \cdot 54\end{array}$ & $\chi^{2}(4)$ & $111 \cdot 19 * * *$ \\
\hline
\end{tabular}

Probability $=0 \cdot 001-0 \cdot 01$. *** Probability $<0 \cdot 001$.

$\dagger$ The number in the brackets refers to the item used as the denominator in the variance ratio or $\chi^{2}$ test of significance.

For final height there is a highly significant joint linear regression over all environmental sets and no evidence that the linear regression slopes differ among the sets. There is a significant non-linear portion of the interaction (remainder item), but this is very small compared with the linear portion (joint regression item). We may therefore estimate a single joint regression coefficient for all the environments which accounts for 86 per cent. of the genotype $\times$ environment interactions. This has a value of +0.20 for line 42 and -0.20 for 2 , thus confirming the greater sensitivity of 42 to environmental variation within the sets.

For flowering time the situation is quite different. There are highly significant differences between the linear regressions in the five environmental sets (heterogeneity of regression item) and the joint linear regression is not significantly greater than this heterogeneity (table 4). There is again a small though significant non-linear component (remainder item). For their relative linear sensitivities, therefore, the lines differ from one environmental set to another. The linear regression coefficients for the two inbreds in each of the five environmental sets are given in table 4 . The reason for their heterogeneity is now clear. The linear regression coefficients vary from -0.25 to +0.91 for 2 and from 0.25 to -0.91 for 42 , which confirms that 2 is the more sensitive in most of the environments. Most of the differences between the regressions, however, is between the successive sowings (sets 2 and 3 in table 4), on the one hand, and the fertilisers (sets 4 and 5) on the other. The three degrees of freedom for heterogeneity among 
these four regressions has, therefore, been partitioned in table 5 into one degree of freedom for the heterogeneity between the successive sowings and the fertiliser sets $(2+3$ versus $4+5)$ and two degrees of freedom for the heterogeneity between the two sets of successive sowing and between the two sets of fertiliser environments ( 2 versus 3 and 4 versus 5). As expected, all the significant heterogeneity among the four linear regressions is attributable to the difference between the successive sowings and the fertiliser sets of environments. There is no difference between the two sets of successive sowings arising from their growth in different seasons or between the two fertiliser sets arising from the presence and absence of lime. We may, therefore, obtain joint linear regression coefficients for the genotype $x$

TABLE 5

Foint linear regression analysis of the genotype $\times$ environment interation in sets 2, 3, 4 and 5 for flowering time in lines 2 and 42

Item D.F. M.S. Test P

1. Joint regression

$1 \quad 187.99$

$\begin{array}{lrr}\text { V.R. }(2) \dagger & <1 & \text { N.S. } \\ \text { V.R. }(3+4) & 13 \cdot 51 & * *\end{array}$

2. Heterogeneity of regression

$1 \quad 201.63 \quad$ V.R. $(3+4) 13.51$ between sowing and fertiliser sets

3. Heterogeneity of regression within sowing and fertiliser sets

4. Remainder

5. Error

$\begin{array}{rrrrr}2 & 20.78 & \text { V.R. (4) } & 1.44 & \text { N.S. } \\ 24 & 14.44 & \chi^{2}(5) & 65.97 & * * * \\ 718 & 5.25 & & & \end{array}$

** Probability, $\mathrm{P}=0 \cdot 001-0 \cdot 01$. *** Probability, $\mathrm{P}<0.001$.

$\dagger$ The number in the brackets refers to the item used as the denominator in the variance ratio or $\chi^{2}$ test of significance.

environment interaction in the successive sowings and in the fertiliser sets of environments. These are -0.05 and 0.82 for line 2 and 0.05 and -0.82 for line 42, respectively.

(ii) $F_{1} s$

In four of the environmental sets $(2,3,4$ and 5$)$ the two reciprocal $F_{1} s$ of lines 2 and 42 were also grown (section 4 ). Since the reciprocal crosses did not differ for either final height or flowering time they have been pooled in all the analyses. The means for these two characters in each of the eight environments for each of the four sets are given in table 6 . The mean height and flowering time for environment 1 in set 2 have been estimated as no $F_{1}$ was grown. They were estimated by adding the mean deviation of all $F_{1} s$ from their midparent values in the remaining environments in the same set to the midparent value in environment 1 . The degrees of freedom available have been modified accordingly.

The analyses applied to the inbred parents are applicable to their $\mathbf{F}_{\mathbf{1}}$ with one modification, namely, that the environmental values used to partition the genotype $x$ environment interactions into linear and non-linear portions must be derived from the inbred parents and not from the $F_{1}$ itself (Bucio Alanis, Perkins and Jinks, 1969; Freeman and Perkins, 1971). An analysis of variance shows that for both characters there are significant differences among the environments within the four sets as well as differences among the sets. The variances of the means over the eight environments within each set are given for both characters in table 7. For final height, 
the four variances are of the same order as, or greater than, those of the inbred parent 42 which is the more sensitive of the two parents (table 3 ). For flowering time the situation is more complex. For the successive sowings

TABLE 6

(a) Means for the final height of the $F_{1}$ between inbreds 2 and 42 in each of 8 environments for each of 4 environmental sets

\begin{tabular}{|c|c|c|c|c|}
\hline \multirow[b]{2}{*}{ Environment } & \multicolumn{4}{|c|}{ Environmental set } \\
\hline & 2 & 3 & 4 & 5 \\
\hline 1 & $136 \cdot 11$ & $114 \cdot 15$ & $32 \cdot 00$ & $75 \cdot 65$ \\
\hline 2 & $127 \cdot 65$ & $117 \cdot 45$ & $59 \cdot 05$ & $69 \cdot 05$ \\
\hline 3 & $133 \cdot 60$ & $124 \cdot 70$ & $50 \cdot 50$ & $70 \cdot 60$ \\
\hline 4 & $120 \cdot 00$ & $126 \cdot 50$ & $48 \cdot 95$ & $70 \cdot 00$ \\
\hline 5 & $121 \cdot 45$ & $132 \cdot 00$ & $53 \cdot 30$ & $61 \cdot 40$ \\
\hline 6 & $115 \cdot 15$ & $135 \cdot 50$ & $37 \cdot 40$ & $57 \cdot 55$ \\
\hline 7 & $110 \cdot 70$ & $141 \cdot 60$ & $62 \cdot 95$ & $72 \cdot 00$ \\
\hline 8 & $102 \cdot 55$ & $139 \cdot 80$ & $71 \cdot 50$ & $65 \cdot 80$ \\
\hline \multicolumn{5}{|c|}{$\begin{array}{c}\text { (b) Means for the flowering time of the } F_{1} \text { between inbreds } 2 \text { and } 42 \text { in each of } \\
8 \text { environments for each of } 4 \text { environmental sets }\end{array}$} \\
\hline & \multicolumn{4}{|c|}{ Environmental set } \\
\hline Environment & 2 & 3 & 4 & 5 \\
\hline 1 & $89 \cdot 04$ & $91 \cdot 55$ & $89 \cdot 80$ & $86 \cdot 65$ \\
\hline 2 & $91 \cdot 50$ & $87 \cdot 85$ & $92 \cdot 20$ & $84 \cdot 85$ \\
\hline 3 & $92 \cdot 75$ & $84 \cdot 40$ & $89 \cdot 70$ & $86 \cdot 50$ \\
\hline 4 & $88 \cdot 65$ & $80 \cdot 60$ & $93 \cdot 60$ & $86 \cdot 50$ \\
\hline 5 & 86.95 & $82 \cdot 30$ & $91 \cdot 70$ & $85 \cdot 90$ \\
\hline 6 & $82 \cdot 45$ & $74 \cdot 50$ & $89 \cdot 20$ & $86 \cdot 65$ \\
\hline 7 & $80 \cdot 65$ & $76 \cdot 65$ & $90 \cdot 70$ & $86 \cdot 40$ \\
\hline 8 & $79 \cdot 55$ & $78 \cdot 30$ & $89 \cdot 70$ & $88 \cdot 85$ \\
\hline
\end{tabular}

the $F_{1}$ variances are the same order of magnitude as those of the more sensitive parent, line 2 , but for the fertilisers they are smaller than those of the less sensitive parent, line 42 .

\section{TABle 7}

The means and variances of the eight environments within each of sets 2 to 5 for final height and flowering of the $F_{1}$. Also the linear regression coefficients $(\beta)$ for the linear component of the genotype $\times$ environment interaction for flowering time

\begin{tabular}{|c|c|c|c|c|c|}
\hline \multirow[b]{2}{*}{ Set } & \multicolumn{2}{|c|}{ Final height } & \multicolumn{2}{|c|}{ Flowering time } & \multirow[b]{2}{*}{$\beta$} \\
\hline & Mean & Variance & Mean & Variance & \\
\hline 2 & $120 \cdot 90$ & $152 \cdot 19$ & $86 \cdot 44$ & $29 \cdot 04$ & 0.06 \\
\hline 3 & $128 \cdot 96$ & $100 \cdot 76$ & $82 \cdot 02$ & $33 \cdot 11$ & 0.09 \\
\hline 4 & $51 \cdot 96$ & $168 \cdot 03$ & $90 \cdot 83$ & $2 \cdot 37$ & $-0.96 * * *$ \\
\hline 5 & $67 \cdot 76$ & $34 \cdot 79$ & $86 \cdot 54$ & $1 \cdot 24$ & $-0 \cdot 85 * * *$ \\
\hline
\end{tabular}

The joint regression analysis of final height agrees with that of the parental lines (table 4) in showing no heterogeneity of linear regressions over the four sets of eight environments. A single linear regression coefficient of $0 \cdot 19$, therefore, defines the linear component of the genotype $\times$ environment 
interactions within the four environmental sets. The linear sensitivity of the $F_{1}$ is greater than that of its more sensitive parent, line 42 , which has a linear regression coefficient of $0 \cdot 14$ over the same four sets of environments. There is also a non-linear component of the interaction in the $F_{1}$ which like that in the parental lines is relatively small but significant (remainder item, $\mathrm{P}=0 \cdot 02-0 \cdot 0 \mathrm{I})$.

The corresponding analysis for flowering time also agrees with that of the parental lines (table 4) in showing highly significant heterogeneity of the linear regressions over environmental sets and no significant joint regression. Once again this heterogeneity is attributable entirely to the difference between successive sowings on the one hand and fertilisers on the other. The joint regression for the two sets of successive sowings is 0.08 and for the two sets of fertilisers is -0.90 . They are comparable in magnitude to the linear regression coefficients for the more sensitive and less sensitive parent in the successive sowings and fertiliser sets, respectively. There is also a relatively small but non-linear component of the genotype $x$ environment interactions comparable to that for the parental lines (table 4).

TABLE 8

The average microenvironmental variance of each set for final height and flowering time of lines 2, 42 and their $F_{1}$

\begin{tabular}{|c|c|c|c|c|c|c|}
\hline \multirow[b]{2}{*}{ Set } & \multicolumn{3}{|c|}{ Final height } & \multicolumn{3}{|c|}{ Flowering time } \\
\hline & 2 & 42 & $\mathrm{~F}_{1}$ & 2 & 42 & $F_{1}$ \\
\hline 1 & 31.92 & $94 \cdot 53$ & - & $14 \cdot 48$ & 14.09 & - \\
\hline 2 & 56.79 & $117 \cdot 28$ & $221 \cdot 74$ & 48.99 & $19 \cdot 25$ & $24 \cdot 35$ \\
\hline 3 & $39 \cdot 92$ & 137.78 & $91 \cdot 25$ & 93.88 & 13.95 & 18.88 \\
\hline 4 & 36.98 & $48 \cdot 29$ & $28 \cdot 66$ & $190 \cdot 92$ & $28 \cdot 36$ & $45 \cdot 39$ \\
\hline 5 & 38.91 & $49 \cdot 80$ & $56 \cdot 23$ & $104 \cdot 28$ & $14 \cdot 19$ & 24.98 \\
\hline
\end{tabular}

(iii) Micro- and supra-macroenvironmental variation

The primary aim of the experiments and their analysis was the interaction of the genotypes with the macroenvironmental variation among the eight environments within the five sets. They also provide information on the interaction at the microenvironmental (within macroenvironment) and at the supra-macroenvironmental level (between macroenvironmental sets). The microenvironmental variances are the variances within families within each macroenvironment. There are 40 such variances for each inbred line ( 8 environments in each of 5 sets) and 32 for the $F_{1}$ (8 environments in each of 4 sets).

For final height line 42 has in general the larger microenvironmental variances. It is significantly the larger $(\mathrm{P}<0.05)$ in 14 out of the 40 pairs of comparisons and it is significantly the smaller in none. There is, however, a contrast between the seasons and successive sowings (sets 1, 2 and 3) and fertiliser (sets 4 and 5 ) in this respect which is summarised by the average variance within these sets given in table 8 . Thus in the former three sets line 42 is on average two to three times more variable than line 2 , while for the latter two sets the average variance of line 42 is only a third larger than that of line 2. Taken overall, therefore, line 42 is more sensitive to microenvironmental variation, as it was to macroenvironmental variation. 
The contrast between sets 1,2 and 3 and sets 4 and 5 at the microenvironmental level is not, however, reflected by any detectable differences between them at the macroenvironmental level.

For flowering time line 2 has the larger variance in all environments within sets 2, 3, 4 and 5, being significantly larger in 15 of the 32 environments within these four sets. In set 1 , however, the variances of lines 2 and 42 are identical, within their sampling errors, in all eight environments. This is shown quite clearly by the average variance for each set given in table 8. There is again a contrast between the relative sensitivities of the two lines to successive sowings and fertilisers which is the reverse of that noted earlier for final height. Overall there is a marked similarity between these results based on microenvironmental variation and those found earlier for macroenvironmental variation including the contrast between the two kinds of environmental sets (tables 3 and 5).

For their microenvironmental variances the $F_{1}$ on average resembles its sensitive parent, line 42 , for final height and its insensitive parent, line 2, for flowering time, which again corresponds with the overall relationships at the macroenvironmental level. If, however, we look at sets individually this simple correspondence breaks down for final height (table 8). Thus we find every conceivable relationship from the $F_{1}$ variances being considerably larger than those of parent 42 in set 2 to the $F_{1}$ variances being somewhat smaller than those of parent 2 in set 4 . Since these different relationships are not consistent within the two pairs of sets (2 and 3, and 4 and 5) no simple pattern emerges.

A further indication of the relative sensitivities of the inbred lines and their $F_{1}$ can be obtained from a test of the homogeneity of the microenvironmental variances over the macroenvironments. For flowering time no clear differences emerge, for all three genotypes the microenvironmental variances are highly heterogeneous over the macroenvironments (Baitlett test, $\mathrm{P}<0.001)$. For final height, however, the microenvironmental variances of line 2 are homogeneous over all environmental sets while for line 42 and $F_{1}$ they are highly heterogeneous $(P<0.001)$. This is additional evidence of the relative insensitivity of line 2 to both micro- and macroenvironmental variation for the character, final height.

The interaction between the two inbred lines and the environmental differences among the five sets is analysed in table 2. For final height this interaction (item 3 ) is not significant. Inclusion of the $F_{1}$ in this comparison does not alter the result. The three genotypes do not, therefore, differ in their sensitivities to variation at the supra-macroenvironmental level. For flowering time, however, the situation is quite different. The interaction of the inbred lines is significant (table 2, item 3). We may examine this further by calculating the variance of each line over the sets. The variances are 189.6 and 3.2 for lines 2 and 42 , respectively. The corresponding variance for the $F_{1}$ is $12 \cdot 9$. Thus, at the supra-macroenvironmental levels, as at the micro- and macro-environmental levels, line 2 is the most sensitive and the $F_{1}$ resembles its more insensitive parent, line 42 .

\section{General and specific effects}

The generality or specificity of the reaction of the two inbred lines and their $F_{1}$ to different kinds of environmental variation can be considered 
from three different viewpoints. We can consider them in terms of the two characters, the three kinds of macroenvironments and the three levels of environmental variation.

In terms of the characters, final height and flowering time, the reactions of the genotypes are largely specific. For example, for final height, line 2 is the least sensitive of the three genotypes to environmental variation of all kinds at all levels whereas for flowering time, line 2 is the most sensitive to the environmental variation in the majority of situations (tables 3,7 and 8 ). The reactions of the genotypes are, therefore, specific to the character. This conclusion is reinforced by consideration of the gene action involved. For final height the $\mathbf{F}_{\mathbf{1}}$ resembles its more sensitive parent in its reaction to macroenvironmental variation. Dominance is, therefore, predominantly for higher sensitivity. For flowering time, on the other hand, the $F_{1}$ is like its less sensitive parent at the macroenvironmental level for fertilisers but like its more sensitive parent for successive sowings. Hence dominance is for lower sensitivity in the former environments and for higher sensitivity in the latter environments. Again at the supra-macroenvironmental level there are no detectable differences among the three genotypes for final height but dominance is for lower sensitivity for flowering time.

In terms of the three kinds of macroenvironments the three genotypes show both general and specific reactions. For final height there is no evidence of specific interactions. A single linear regression for each of the three genotypes is a statistically adequate description of its interactions with all three kinds of macroenvironments (table 4). The relative sensitivites of the three genotypes established in one kind of environment are, therefore, directly applicable to the other kinds of environments. We might expect therefore, that selection for a particular level of reaction of final height to environmental variation in one kind of environment would lead to selected genotypes with a similar level of reaction to the other kinds of environments.

For flowering time there is evidence of considerable specificity in the reactions of the genotypes to the different kinds of environmental variation. Thus there are highly significant differences in the relative sensitivities of the three genotypes to the two sets of successive sowings and the two sets of fertilisers (table 5). Selection for a desired level of reaction in one of these two kinds of environments would not be expected to lead to the same level of reaction in the other. Equally, of course, insensitivity of flowering time to variation in sowing date can be combined with a high rate of change to added fertiliser.

In terms of the three levels of environmental variation, micro-, macroand supra-macro, there is considerable general interaction among the genotypes. Thus at both the micro and macro levels line 42 is more sensitive than line 2 for final height, equally at all three levels line 2 is in general the more sensitive for flowering time. Hence, selection for a high or low reaction to the environment at one level might be expected to lead to changes in the same direction at the other levels.

These expectations are currently being tested by selection among the progeny of a related cross (between varieties 2 and 12) for high and low sensitivity to differences in sowing date for final height and flowering time. 


\section{Summary}

1. Genotypes selected for their high and low interactions with seasonal differences are compared for their interaction with environmental variables, sowing dates and fertiliser applications.

2. The genotypes are two inbred lines of Nicotiana rustica and their reciprocal $F_{1}$ s. Final height and flowering time were scored.

3. Five sets of environments were used, eight seasons, eight sowing dates in each of two seasons and two sets of eight factorial fertiliser treatments, one with and one without lime.

4. Most of the genotype $\times$ environment interaction between the environments within each set can be accounted for by linear regressions on the additive environmental values.

5. For final height a single linear regression accounts for the interaction with the eight environments of all five sets. For flowering time significantly different linear regressions are required for the different kinds of environmental sets.

6. For final height dominance is in the direction of greater sensitivity to the environment while for flowering time it is in the direction of lower sensitivity to some kinds of environments and greater sensitivity to others.

7. In general, the relative sensitivity of the genotypes to environmental variation are consistent over the micro-, macro- and supra-macroenvironmental levels.

8. The overall results suggest that different characters are independent in their reaction to the environment.

9. Selection for a desired level of sensitivity of final height in one environment is expected to lead to a similar level of sensitivity in other environments.

10. Selection for sensitivity to one kind of environment for flowering time can be combined with selection for insensitivity to a different kind of environment.

11. Both the situation for final height and that for flowering time have potential advantages and disadvantages when designing a programme to select for a desired level of sensitivity to the environment. These are being investigated in a selection experiment.

\section{REFERENCES}

BUCIO-ALANIS, L., PERKins, JEAN M., AND JINKS, J. L. 1969. Environmental and genotypeenvironmental components of variability. V. Segregating generations. Heredity, 24, 115-127.

FINLAY, K. W., AND WILKINson, G. N. 1963. The analysis of adaptation in a plant breeding programme. Aust. 7. Agric. Res., 14, 742-754.

FREEMAN, G. H., AND PERKINS, JEAN M. 1971. Environmental and genotype-environmental components of variability. VIII. Relations between genotypes grown in different environments and measures of these environments. Heredity, 27 (in press).

JINKS, J. L., AND MATHER, K. 1955. Stability in development of heterozygotes and homozygotes. Proc. Roy. Soc., B, 143, 561-578.

MATHER, K. 1946. The genetical requirements of bio-assays with higher organisms. Analyst, $71,407-411$.

MATHER, K. 1953. The genetical control of stability in development. Heredity, 7, 297-336. PERKINS, JEAN M., AND JINKS, J. L. 1968a. Environmental and genotype-environmental components of variability. III. Multiple lines and crosses. Heredity, 23, 339-356. 
PERKINS, JEAN M., AND JINKS, J. L. 1968b. Environmental and genotype-environmental components of variability. V. Non-linear interactions for multiple inbred lines. Heredity, 23, 525-535.

thoday, J. M. 1953. Components of fitness. Symp. Soc. Exp. Biol., 7, 96-113.

WESTERMAN, JANE M., AND LAWRENCE, M. J. 1970. Genotype-environment interaction and developmental regulation in Arabidopsis thaliana. I. Inbred lines; description. Heredity, 25, 609-627. 